\title{
SÁHARA OCCIDENTAL - TIMOR ORIENTAL ¿GEMELOS HACIA LA PAZ?
}

\author{
D. ${ }^{a}$ Ilde Garcia Felipe \\ Asociación Internacional de Juristas para el Sáhara Occidental \\ (IAJUWS)
}

\begin{abstract}
Portugal-Indonesia-Tìmor Oriental; España-Marnecos-Sáhara Occidental.

Parece consagrarse una trágica constante en la sucesión de Estados: es rentable radicalizar la tensión por el invasor sobre el Territorio No Autónomo - al menos, cuando éste conserva su importancia económica y/o estratégica-; ello le permite, en el caso de que la independencia devenga inexorable, no sólo arrancar del nuevo poder la amnistia sobre los crimenes cometidos, sino perpetuar la permanencia de los colonos, respetar sus propiedades -frecuentemente además, sobre sectores estratégicos-, conferirles -convirtiendo el hecho en derecho- una cuota politica en el poder del Estado que nace, reteniendo la alianza con las multinacionales y configurando, en uiltima instancia, un Estado filo-imasor: Asi sucedió en Timor Oriental y asi está ocurriendo en el Sáhara Occidental.
\end{abstract}

Solemos referirnos a los conflictos de Timor Este y del Sáhara Occidental como conflictos gemelos. El paralelismo entre ambas cuestiones es, en efecto, evidente.

Timor Este y Sáhara Occidental han sido, el Sáhara sigue siéndolo, Territorios No Autónomos, objeto primero de dominio colonial y, a continuación, de ocupación militar, consecuencia desgraciada de una descolonización inacabada; y en los dos, sus pueblos quedaron sin ejercer durante más de dos décadas, el saharaui aún pendiente, el derecho a la libre determinación, del cual son titulares.

Coincide la decisión de ambas potencias ocupantes, Indonesia y Marruecos-los dos, países paradógicamente recientemente descolonizados-, de modificar la composición étnica de Timor y Sáhara. Así, la administración Indonesia adoptó medidas que incidieron muy gravemente en la evolución del problema, al favorecer la llegada de inmigrantes indonesios a Timor, al tiempo que facilitaba la esterilización de mujeres timorenses, aunque el territorio no estaba densamente poblado, especialmente después del genocidio. Mientras, el régimen marroquí organizaba sucesivas "Marchas" de colonos hacia el Sáhara, hasta llegar a 
300.000 ocupantes, entrañando tales migraciones una alteración grave del status demográfico del territorio, y con el objetivo de modificar la composición étnica de la población.

De otra parte, las semejanzas en la cronología (Marruecos invadió el Sáhara en Noviembre de 1.975 e Indonesia invadió Timor Este al mes siguiente), en el desequilibrio demográfico entre los contendientes, la situación periférica de ambos territorios dentros de los imperios ibéricos a los que pertenecieron, y la incidencia directa de las crisis politicas de los dos Estados ibéricos sobre los procesos de descolonización.

Por último, en los últimos veinticinco años, en ambos conflictos la desaparición temporal o permanente en reclusión secreta ha afectado a miles de personas por ejercer pacificamente su libertad de expresión y movimientos. Desapariciones que van acompañadas de torturas y todo tipo de tratos crueles, inhumanos y degradantes. En el caso de Timor Este, más de 200.000 timorenses, de una población inicial de 700.000 , perdieron la vida durante el primer año de la invasión indonesia, que no dudo, además, en esquilmar las riquezas naturales de Timor y que han financiado, en buena medida, la perpeutación del propio conflicto.

Portugal dio inicio a un proceso de descolonización que preveía la consulta al pueblo timorense, pero Indonesia, mediante la vis fisica, consiguió interrumpirlo. La acción del Gobierno portugués se centró, entonces, en romper las relaciones diplomáticas con Indonesia el mismo día de la invasión y denunciar la situación ante el Consejo de Seguridad de las Naciones Unidas, aspectos que le permitieron mantenerse como potencia administradora, de forma mucho más activa, creíble y eficaz que España en relación al Sáhara Occidental.

En este sentido Portugal, en Febrero de 1.991, denunció, como potencia administradora que era, a Australia ante la Corte Internacional de Justicia por el Tratado concluido entre Indonesia y Australia en 1.989 sobre la explotación de una zona marítima que forma parte del territorio de Timor Oriental y denominada Falla de Timor. La Corte, en su Sentencia de 30 de Junio de 1.995, se pronuncia sobre la controversia entre Portugal y Australia, constata la naturaleza de norma erga-omnes del Derecho a la Autodeterminación y la condición jurídica de Territorio No Autónomo de Timor Este, pero se declara no competente para conocer del fondo del asunto al admitir que Indonesia no es parte en el proceso y que no ha reconocido la competencia de la Corte. El paralelismo entre el asunto de Timor y el del Sáhara Occidental se basaría en la utilización de los recursos pesqueros del Sáhara por parte de Marruecos.

Por su parte, España, en la década de los setenta, al firmar el Acuerdo Tripartito de Madrid con Marruecos y Mauritania, abandonó en la práctica el Sáhara Occidental a la administración marroquí. Ese Acuerdo, firmado el 14 de Noviembre de 1.975, era claramente ilegal, ya que una potencia administradora no puede transferir sus obligaciones y poderes a terceros Estados. Pero, a pesar de ser ilegal, afectó a la capacidad de la España democrática para recuperar el ejercicio de sus funciones como potencia administradora.

Aun más que en el caso portugués, la posición de España en relación a su ex colonia del Sáhara, evidencia hasta qué punto los intereses nacionales e internacionales se sobrepo- 
nen frecuentemente sobre los derechos y obligaciones de los Estados en sus relaciones mutuas y, sobre todo, con los pueblos más debiles, desprotegidos y dependientes. Estas realidades nos hacen pensar en la importancia de acciones concertadas de los Gobiernos que apoyan, de hecho, ocupaciones ilegales y presiones de pueblos enteros por Estados totalitarios. Y la responsabilidad de tales ocupaciones (y la debilidad de las administraciones tutelares), es el resultado de las presiones de los Estados más fuertes, los mismos que impunemente bloquean a las Naciones Unidas cuando les conviene y la convierten aparentemente en más eficaz cuando la disponen a su servicio.

En lo que respecta a Timor Este, si la masacre de Santa Cruz, en 1.991, se tradujo en un clamor público en el mundo occidental, la concesión del Premio Nobel de la Paz en 1.996 al Obispo Ximenes Belo y al Doctor Ramos Horta, era la antelasala de la entrevista entre el Presidente Sudafricano Nelson Mandela y el líder timorense Xanana Gusmao, en Yakarta. Por último, el nombramiento por Kofi Annan de un Representante Especial para Timor Este, el Ex-Embajador de Pakistán, Señor Marker, auguraba una época fructífera.

Y efectivamente, mediante los Acuerdos de Nueva York, suscritos en Mayo de 1.999, las Partes negociadoras -Indonesia y Portugal- aceptaban la celebración de un referéndum para Timor Oriental, tomando como base el siguiente cuerpo electoral:

"Tienen derecho al voto quienes, habiendo cumplido 17 años de edad,:

a) Hayan nacido en Timor Este.

b) Los que, habiendo nacido fuera de Timor Este, tengan padre o madre nacidos en Timor Este.

c) Quienes estén casados con alguien integrado en alguna de las dos categorias anteriores".

La Consulta se hizo efectiva el día 30 de Agosto de 1.999. La opción sobre que votar era la siguiente:

"¿Acepta la autonomia especial propuesta para Timor Este, integrada en el Estado Unitario de la República de Indonesia?"

“Rechaza la autonomia especial propuesta para Timor Este, llevando a la separación de Timor Este de Indonesia?"

El resultado del referéndum fue el siguiente:

Votos efectivos: 451.792

Aceptan la autonomia: 94.388 votos (21'5\%)

Aceptan la independencia: 344.580 votos $\left(78^{\prime} 5 \%\right)$

Votos nulos: 7.900

\section{¿ERA PREVISIBLE LO OCURRIDO EN TIMOR?}

Únicamente apuntar tres factores, conocidos a priori:

1. SITUACIÓN INTERNA EN INDONESIA.- Las tensiones internas en el poder indonesio entre el Presidente B. J. Habibie y el hombre fuerte de Suharto, General Wiranto, 
Ministro de Defensa, evidenciaban un pulso que se proyectaba sobre el modo de solución en Timor Este. Quizá Timor, en esa tensión de poder, no tuviera más valor que el simbólico un símbolo extraordinario, cerrar la integridad territorial de un archipiélago de $4.000 \mathrm{kms}$ de anchura con más de 17.000 islas-, un pulso entre la concepción férrea del país hasta entonces y la apertura hacia la democracia, sin olvidar que las fundamentales riquezas de Timor Oriental (petróleo de Timor GAP, pesca, diamantes, etc), estaban directamente vinculadas a los hijos de Suharto. En definitiva, la búsqueda por Wiranto de que la independencia inexorable de Timor fuese controlada por Indonesia hasta el final y que no apareciera como una derrota para el Régimen, por tanto para él, ante los indonesios ni ante la órbita internacional, preservando su influencia en la zona. Ha de añadirse a ello que Suharto y Wiranto se sabían criminales de guerra y que, más temprano que tarde, se promovería acciones contra ellos ante un Tribunal Internacional de Justicia ad hoc.

Saltó a la prensa internacional el llamado "Plan B" elaborado por Yakarta en previsión de una victoria independentista, que incluso entró en cierta fase de aplicación. El plan preveía dividir Timor Oriental en un sector rico y fértil integrado a Indonesia y otro, pobre y despoblado, para los independentistas. Tácticamente Indonesia no hizo más que ampliar el contingente militar en la Isla, formalmente para restaurar el orden público, estratégicamente pretendiendo culminar la limpieza étnica.

En contra, y por ello, algunos mantenían la conveniencia de postergar el referéndum hasta que se hubiera consolidado internamente la situación política indonesia con la desaparición del actual Presidente Habibie del poder, así como de Wiranto, con la asunción del poder por la que se deseaba fuera la nueva Presidenta, Magawati Sukarnoputri.

En resumen, Indonesia apenas había iniciado su transición política desde un Régimen brutal durante tres décadas a otro más democrático y el ayer se imponía aún sobre el mañana. Los poderes de facto se seguian superponiendo a los de derecho. Todo ello se proyectó, cómo no, sobre Timor.

2. POBLACIÓN COLONA.- Como es sabido, se provocó desde 1.975 por Indonesia migraciones sistemáticas de población indonesia a la parte Oriental de Timor, tanto desde Timor Occidental como de otras zonas del Archipiélago (principalmente desde Bali). Decenas de miles de colonos se mezclaron con los autóctonos. Fueron considerados patriotas por el régimen indonesio, dispusieron de todo el poder político y económico, y miles de ellos pudieron votar en el referéndum (recordemos que únicamente se precisaba haber nacido en Timor y contar con 17 o más años de edad).

El futuro de la población colona en el Territorio que iba a independizarse tuvo mayor importancia de la prevista. Ante el anuncio del Movimiento de liberación de que iba respetarse a tal población, nunca se hizo con la suficiente contundencia. Por su parte, al invasor no le convenía asumir esa promesa sino proyectar, en cambio, hasta el final los miedos sobre los suyos: que resultarían represaliados, perderían sus puestos de trabajo y sus pertenencias, sin indemnización y sin futuro. Ese miedo caló más hondo en la población de un país dictatorial que el anuncio de un futuro respeto sin garantías. Esa situación de miedo, de hecho, del colono sencillo, se proyectó en suponer que la represalia vendria, no tanto de las nuevas autoridades timorenses, sino de la misma población independiente. Ese miedo, en definiti- 
va, desencadenó la reacción de los anexionistas -la mayoría de la cual era población colona, cuyo futuro y el de sus familias dependía, siempre según ellos, del grado de defensa que ejercieran ante lo que habían venido escuchando desde dos décadas atrás, "es suyo".

Seguramente faltó en los Acuerdos de Nueva York un pacto anexo, público o secreto aunque explícito, sobre el futuro de la población indonesia radicada en Timor, y sobre Acuerdos económicos y futuro entre países soberanos (para lo cual debiera haber estado presente en la negociación la Parte timorense), y se ha preferido relegarlo, en su caso, a su negociación durante la fase de transición.

Era el problema esencial de un refrendo en que se apostó a una sola carta, en el que una de las Partes va a ganarlo todo y la otra lo perderá igualmente todo, sabiendose, además, de antemano y sin duda, quién va a ser la ganadora y quién la perdedora. De haberse alisado en la negociación del Plan de Paz tales extremos, el Referéndum habria devenido en una suerte de plebiscito con remisión a lo Pactado entre las Partes.

La inseguridad en el territorio fue patente, para los dirigentes timorenses, para los Observadores y periodistas, hasta para la propia

UNAMET y, sobre todo, para la población. No obstante, de estos grupos, todos contaron con una clara posición de privilegio respecto a la población. Los dirigentes se favorecieron de la estrecha protección de la estructura de la CNRT; los Observadores y periodistas, del "privilegio del extranjero": el respaldo de sus respectivas Embajadas, la amenaza ante los indonesios de la injerencia internacional, y, en última instancia, la de una asegurada evacuación; los miembros de la UNAMET, la de contar con el respaldo y la reacción de la Comunidad internacional. Quizá entre todos, en una relativa seguridad, se forzo la situación, aislándose de la realidad circundante que, en caso de fracaso, sufriría inexorable y principalmente la población; sólo los timorenses de a pie permanecerían enteramente a merced de la represión, sin medios con que hacerle frente.

Sobre lo anterior, hubiera sido necesario un dispositivo de presencia internacional armada. La idea del Gobierno filipino de protección con unidades filipinas de los observadores de su pais, aunque integradas en la estructura de la Policía Civil de UNAMET, era correcta.

3. GEOESTRAGIA Y GEOPOLÍTICA.- Parece consagrarse una trágica constante en la sucesión de Estados por la que es rentable radicalizar la tensión por el invasor sobre el Territorio No autónomo -al menos, cuando éste conserva su importancia económica y/o estratégica-; le permite, en el caso de que la independencia devenga inexorable, no sólo arrancar del nuevo poder la amnistía sobre los crímenes cometidos, sino perpetuar la permanencia de los colonos, respetar sus propiedades -frecuentemente además, sobre sectores estratégicos-, conferirles -convirtiendo el hecho en derecho- una cuota política en el poder del Estado que nace, manteniendo la alianza con las multinacionales y configurar, en última instancia, un Estado filo-invasor. Junto a ello, la seria advertencia del Estado invasor evidenciando cómo es capaz de reaccionar ante cualquier otro movimiento secesionista en el interior del país.

Indonesia cuenta con aproximadamente 250 millones de habitantes, es el cuarto pais en extensión del mundo. Sus relaciones económicas como importador de Japón y Korea y como 
exportador respecto a China, así como su arsenal bélico y militar, la convierten en una pieza clave en el equilibrio económico y político en Asia.

El futuro de Timor, de religión cristiana en un contexto islámico, es de gran calado. En las candilejas del proceso de independencia se agazapan los intentos de modificación grave del equilibrio de poderes en Asia. Pretende ser aprovechado por Occidente para adelantar las barreras de influencia australiana en la zona, país al que aparece abocado Timor si quiere distanciarse de su órbita hasta ahora, -nos referimos, lógicamente, a la nueva influencia australiana sobre miles de kilómetros cuadrados si tenemos en cuenta el Mar de Timor y su plataforma continental-, y con ella la entrada de capital occidental. Occidente se instalaria, por vez primera, materialmente en el seno de Indonesia -casi en uno de sus centros geográficos, lo que favorecería un notable incremento de la presencia económica occidental, en detrimento del mercado japonés y, sobre todo, el interés geopolítico de menguar la influencia de China como miembro permanente del Consejo de Seguridad de la ONU y como líder natural en Asia. En la memoria de 1.999 queda el bombardeo de la Embajada china en Belgrado por tropas de la OTAN y las reticencias chinas en el Consejo de Seguridad sobre cómo resolver el problema de la violencia en Timor en los días siguientes al referéndum.

Resumen.- Ciñéndonos a la realidad, sin especulaciones, debe partirse de la siguiente premisa: durante la Campaña electoral, esto es, cuando ya la UNAMET ejercía el mandato de la Comunidad Internacional, se practicó la violencia e intimidación para con la población concernida por el voto. Ante tal situación de hecho, evidentemente contraria al Proceso de Paz, UNAMET reacciona apelando al incremento de presencia y eficacia de la policía indonesia.

Tal incremento efectivamente se produce y, entonces, UNAMET es consciente -o debiera serlo-, de lo siguiente: el incremento de la fuerza policial no resulta más eficaz, no por el aumento de elementos incontrolados, sino porque el Gobierno de Indonesia busca exactamente lo contrario, que sea ineficaz su policía y que deje seguir haciendo a las milicias.

Y UNAMET es consciente -0 debiera serlo-, de tal realidad porque la evidencia de la escalada de la violencia no se está traduciendo en detención alguna por la policía indonesia sino, antes bien, son ostensibles los gestos de la policía apoyando a los milicianos y que, ante los disparos de éstos, se sofocan por la policía simplemente pidiendo que se marchen del lugar.

Junto a lo anterior, UNAMET estaba perfectamente informada de cuál iba siendo la situación exacta en Timor y cuál sería la reacción de las milicias después del referéndum. Las denuncias de los dirigentes de la CNRT y de los informes de la propia UNAMET asi lo anunciaban.

A partir de comprobar la ineficacia deliberada de la policía indonesia, la irresponsabilidad no es ya solo de ésta, sino, lo que es más grave, de la propia UNAMET por su falta de firmeza ante el culpable. Y lejos de atajar, con los medios que hubiese hecho falta, tal situación, paralizando incluso el proceso electoral mientras los obstáculos no se removieran, hizo proseguir el proceso utilizando tan solo las diplomáticas advertencias. Todo ello evidencia, no solo la falta de medidas preventivas, sino aun de represivas en las misiones de la ONU. 
Hay que tener en cuenta, en este sentido, que el despliegue de la fuerza internacional -INTERFET- en las fechas siguientes a la publicación de los resultados de la consutla en Timor Este, por decisión del Consejo de Seguridad, se inscribe en la confirmación por el propio Consejo de Seguridad de la "incapacidad" -la falta de voluntad-, del Gobierno de Indonesia en frenar la violencia. La cuestión es evidente: ¿Por qué no se adoptó tal presencia internacional armada, en el número apropiado, tan pronto como la situación no era controlada por UNAMET, lo que era patente ya en la propia campaña electoral?

A modo de lección, es preciso en estos procesos por la ONU:

- Permanecer atenta a la voluntad real del país invasor sobre el proceso de autodeterminación.

- Mantener el protagonismo de la Misión de la ONU, reaccionando con la firmeza apropiada ante los actos que perturben el clima de tranquilidad preciso.

Como conclusión, cabría colegir que la Comunidad Internacional actuó en Timor Oriental a través de la ONU sin la debida infraestructura, amparándose UNAMET en una "burbuja de cristal" bajo el paraguas del voto de confianza a Indonesia, durante unos días y rigiéndose con criterios estrictamente técnicos sus componentes durante la campaña, el referéndum y el escrutinio, permaneciendo conscientemente ajena la Comunidad a la realidad circundante en Timor. Cuando UNAMET percibió al final que su trabajo no era aceptado por las huestes de la Parte que perdió el referéndum, se retiró abandonando a una población que bien pudiera sentirse burlada por lo que pudo parecer un "juego" que le ha sido organizado por la propia Comunidad Internacional.

El proceso de Timor ha traído a la actualidad el desafío principal del Consejo de Seguridad y de Naciones Unidas a partir de ahora: construir su unidad bajo el principio de que la violación sistemática y masiva de los derechos humanos, alli donde se produzca, no debe permitirse.

En el proceso descolonizador africano, mientras el África francesa, agrupada en las regiones occidental, ecuatorial y oriental del continente, había sido regida por una Administración más vinculada a la evolución de la metrópoli, lo que había propiciado los sistemas de asociación y asimilación, en el África española, centrada en las zonas de Guinea Ecuatorial, Ifni y Sáhara Occidental, se dio una administración colonial que evolucionó de la integración a la provincialización.

El interés español en reforzar su control en la zona precisaba, urgentemente, frenar el expansionismo neocolonialista marroqui. $Y$ su insensibilidad histórica, en un contexto internacional de emancipación de los pueblos, le impulsa a convertir el territorio en provincia. El Decreto de Presidencia de 10 de Enero de 1.958, reorganiza el Gobierno de África Occidental española: Los territorios del Africa Occidental Española se hallan integrados por dos provincias, denominadas Ifni y Sáhara español (Articulo $1^{\circ}$ ).

Durante la vigencia de tal legislación, los saharauis son titulares del Documento Nacional de Identidad, viajan al extranjero con pasaporte español, acceden a la Administración Pública - ifuncionarios y no españoles?- pueden ser militares y, en tal caso, 
juran ante la bandera defender la Patria, e intervienen en los escasos refrendos convocados por el Régimen, como el de 1.966, relativo a la Ley Orgánica del Estado. Como Provincia, los Procuradores la representan ante las Cortes Generales, y tales Procuradores no defienden a la población estrictamente saharaui, sino a toda la población del Sáhara. ¿Podian ser los Procuradores en Cortes no españoles?

En Julio de 1.975, Henry Kissinger, Secretario de Estado norteamericano, mientras descansa en un lujoso complejo residencial de las Islas Vírgenes, ojea el informe facilitado sobre la situación del Mediterráneo. Por el Este se anuncia el estallido bélico de Israel con sus vecinos. Por Occidente, un nuevo conflicto, el del Sáhara. La evaluación de inteligencia de la estación de la CIA en Rabat sobre la situación interna en Marruecos, fechada en Junio, indica que la reivindicación territorial marroquí sobre el Sáhara está en punto muerto. La ONU había dictaminado a favor de la descolonización y un referéndum de autodeterminación de la población saharaui; sin embargo, las Partes no se ponen de acuerdo en el censo de la población sobre el que convocar la Consulta. Mientras tanto, Argelia apoya a un partido nacionalista, el Frente POLISARIO, que se muestra cada vez más activo. Por último, España está debilitada por la salud del General Franco, a lo que hay que sumar el lobby pro argelino integrado por dirigentes del régimen franquista con importantes relaciones económicas con Argel a través de importantes contratos de gas natural y obras públicas, que imposibilitan el desbloqueo diplomático.

Los asesores de Kisinger, ayudados por oficiales marroquíes que forman un selecto y reducido servicio de información creado por el propio Hassan, sentencian: Estados Unidos debe ayudar a Marruecos forzando la devolución del Sáhara Occidental a Hassan II, como medio de estabilizarle en el trono. En el mismo informe se analiza que así Argelia no obtendrá una salida al Atlántico, que habia que evitar la presencia de un movimiento de liberación "afin a los intereses de Moscú" frente al importante espacio geoestrátegico del archipiélago canario, retaguardia de la OTAN y paso obligado de las rutas del petróleo árabe que converge en Europa.

Dos días más tarde, Kissinger recibe una carpeta que le llega desde Washington, en la que se dice escuetamente: "Sáhara: Marcha Blanca"-por el color de las chilabas-. La operación consistía en una gran marcha, a través del desierto, de unas trescientas mil personas, que llegarían a la frontera española del Sáhara para forzar la firma de un acuerdo entre Madrid y Rabat, al margen de las recomendaciones de la ONU, que comprometiese al Gobierno de Madrid a abandonar la soberanía sobre el territorio y retirar sus fuerzas militares. Despúes del último atentado contra Hassan II, convenía arropar la propia estabilidad del trono. Una marcha multitudinaria de componente religioso en torno a su jefe espiritual, en la que participan partidos de izquierda, que apoyan al Rey en la cuestión del Sáhara, independientemente del resultado final de la misma, se juzgaba fortalecía la figura del Monarca. La operación costaría unos veinte millones de dólares. Se sugería que el Embajador norteamericano en Ryad sondeara la predisposición del Rey saudita a financiar una parte de los gastos.

Kissinger aprueba el proyecto. La estación de la CIA en Rabat había enlazado semanas atrás con el Pentágono solicitando la realización de unas maniobras de la US Navy frente a 
las costas marroquies, en colaboración con las Fuerzas Armadas Reales, que sirvieran de tapadera a los movimientos de aprovisionamiento logísticos a realizar. El objetivo es que ni los servicios de información militares españoles del Alto Estado Mayor, con "antenas" en Marruecos, descubrieran lo que se estaba tramando. Si los agentes españoles detectaban, entre otros preparativos, la compra masiva de bidones para almacenar agua, sería achacada a las maniobras (Extracto de "Historia de la transición", Diario 10).

El Estado español ha venido ejerciendo, como Potencia administradora, plenitud de competencias y facultades sobre el territorio no autónomo del Sáhara, que durante algunos años ha estado sometido en ciertos aspectos de su administración a un régimen particular con analogias al provincial y que nunca ha formado parte del territorio nacional. Próximo a culminar el proceso de descolonización de dicho territorio, de conformidad con lo establecido en la Carta de las Naciones Unidas, procede promulgar la norma legal adecuada para llevar a buen fin dicho proceso y que faculte al Gobierno para adoptar las medidas al efecto.

En su virtud y, de conformidad con la Ley aprobada por las Cortes españolas,

Vengo a sancionar:

Articulo único. Se autoriza al Gobierno para que realice los actos y adopte las medidas que sean precisas para llevar a cabo la descolonización del Sáhara, salvaguardando los intereses españoles.

El Gobierno dará cuenta razonada de todo ello a las Cortes.

...

Dada en el Palacio de la Zarzuela a diecinueve de Noviembre de mil novecientos setenta y cinco.

JUAN CARLOS DE BORBON

Principe de España.

Los Preámbulos carecen de eficacia normativa, por lo que la declaración incluida en la Ley de Descolonización del Sáhara acerca de que el Sáhara nunca ha formado parte del territorio nacional, es nula.

Respecto a la autorización -orden-, al Gobierno para que realice los actos y adopte las medidas precisas para llevar a cabo la descolonización del Sáhara salvaguardando los intereses españoles, ningún Gobierno a partir de entonces la ha cumplido. Descolonizar implicaba organizar un Refrendo de autodeterminación y no -tal como debió entender, quizá (i), el Ejecutivo- evacuar a sus colonos del territorio.

Se reconoce el derecho a optar por la nacionalidad española a los naturales del Sáhara que, residiendo en territorio nacional estén provistos de documentación general española, que encontrándose fuera de él se hallen en posesión del Documento Nacional de Identidad bilingüe expedido por las autoridades españolas, sean titulares del pasaporte español o estén incluidos en los registros de las representaciones españolas en el extranjero (artículo primero del Real Decreto 2258/1.976, de 10 de Agosto, sobre opción de la nacionalidad española por parte de los naturales del Sáhara). 
Con la publicación de este Decreto se violó razones superiores de Derecho Internacional, al no respetar el Convenio sobre el Estatuto de los Apátridas, de 1.954, y la Convención para reducir los casos de Apatridia, de 1.961, Pactos por los que los Estados no deben privar a ninguna persona de su nacionalidad si esa privación ha de convertirla en apátrida, y la obligación de los Estados de no privar a las personas de su nacionalidad por motivos raciales, étnicos, religiosos o políticos, señalando además que, en caso de cualquier transferencia de un territorio, se incluirá disposiciones para asegurar que ninguna persona se convertirá en apátrida como consecuencia de dicha transferencia: más aún en el caso que nos ocupa, en el que no produjo nunca ninguna transferencia legal del territorio.

En el Derecho interno español cabe citar los artículos 19 y ss del Código Civil, en cuanto a la determinación de que la nacionalidad española que ostentaban los saharauis lo era de origen y no por naturalización, dado que nacieron en la entonces denominada Provincia del Sáhara, a todos los efectos territorio español y siendo propiamente territorio español, pues la posesión de los territorios saharianos por España se remontan al Siglo XIX; tras la expedición de Bonelli, una Orden de Diciembre de 1.884 ya lo declaraba zona de influencia, la cual fue reconocida internacionalmente en el año 1.886 y, más tarde, en el Tratado de París de 1.904.

Últimamente incide en la nacionalidad española de los saharauis, admitiéndola y estableciendo que el Sáhara era territorio español, la Sentencia del Tribunal Supremo de España, de fecha 7 de Noviembre de 1.999.

En 1.975 el principio era la aceptación del poder de Francia en la región y la alianza generalizada entre Marruecos con la órbita occidental y con EEUU.

Veinticinco años después, dos factores nuevos concurren: de una parte, aquel pequeño pueblo saharaui, del que nadie en la Comunidad Internacional parecía apostar siquiera por su superviencia, no solo resistió sino que fue reconocido como una de las dos Partes legitimadas en el Proceso de Paz para el Sáhara Occidental. De otra, la estructura geopolítica es radicalmente otra y ahora aconseja la autodeterminación de la última colonia africana.

Lo magnífico y lo enconado del Proceso de Paz para el Sáhara es que, en realidad, se ha concebido como Plan de Paz para todo el Magreb. No es baladí que estén involucrados los cuatro países de la zona: Frente POLISARIO y Marruecos como Partes en el referéndum, Mauritania y Argelia como Países Observadores Oficiales. La visita de James Baker el 12 de Abril de 2.000 a Madrid y seguidamente a París, en la interpretación periodística al menos, reafirmaba la intención del Enviado Personal del Secretario General de la ONU de involucrar a España y Francia en el desbloqueo del Plan de Paz sobre el Sáhara Occidental.

Mediante los Acuerdos de Houston, pactados entre el Frente POLISARIO y Marruecos en 1.997, se ha formateado el último trecho hacia la autodeterminación para el Sáhara Occidental. Un experimento inédito en el que, por vez primera en la moderna historia, una de las dos Partes afectadas por un Referéndum, con una población dividida entre el exilio forzado y la represión, a la que se permite 2.000 elementos de un ejército dislocado al Este del territorio, se enfrentará electoralmente a un Régimen que mantiene invadido militar- 
mente el territorio desde 1.975 , con al menos 200.000 colonos y que dispondrá de una fuerza militar de 65.000 miembros al Oeste del Sáhara Occidental e incólume su policía.

Antes de que dé comienzo el denominado Período de Transición, se habrá dado contestación a varias cuestiones en la fase de identificación. Difíciles y sutiles cuestiones: ¿en cuánto resultará ampliado el Censo del 74?; ¿para qué habrá servido desviar un censo demográfico hacia un censo pretendidamente étnico -no hay prueba bastante del origen saharaui de miles de candidatos propuestos por la Parte marroqui, sino la certeza de su idiosincrasia marroqui $y$, consiguientemente, del sentido de su voto en la futura Consulta-, que acoja a gentes que no hablan el hassania ni visten la darraa o la melhfa? La sensatez siempre se impone.

En realidad, el Plan de Paz no es más que la última escena de una obra sangrienta e innecesaria, cuyo desenlace, por lógico y por imprescindible para completar el puzzle en el Magreb, ha sido gritado al mundo hace veinticuatro años ya con el éxodo del pueblo saharaui. ¿Era necesaria tal parafernalia? Si se fuese lealmente consecuente con un censo, demográfico y étnico a la vez, la Consulta devendría, en realidad, gratuita y segura en su resultado: como cualquier otro pueblo, todo saharaui de origen apostaria por un Sáhara independiente, oficializar, perpetuar la condición de la que disfrutó históricamente su territorio. Lo otro, la "fabricación" de saharauis para decantar la Consulta a favor de la integración en Marruecos, es algo artificioso y ex novo, tras la invasión militar de 1.975.

Los últimos informes del SG de la ONU se han venido refiriendo a la aceptación por el Régimen marroquí de la presencia de ACNUR, al Estatuto para el despliegue integral de MINURSO, al despliegue de la unidad de remoción de minas, a la identificación y al proceso de apelaciones.

En su Informe de 17 de Febrero de 2.000, Kofi Anan efectúa un resumen de cuál es la situación de los votantes hasta ahora:

Primera lista: Comenzo en 1.994. Se ha identificado a 147.249 requirentes y se ha admitido finalmente a 84.251 personas en la lista provisional que se ha hecho pública en fecha de 15 de Julio de 1.999.

Segunda lista: Identificación de los grupos tribales H41, H61 y J51/52. La identificación comenzó en fecha de 15 de Junio de 1.999 y concluyó el 30 de Diciembre. La MINURSO interrogó a 51.220 requirentes. El día 17 de Enero de 2.000 se publica la lista de los admitidos como votantes de estos grupos: 2.135.

Salvo la entrada en vigor del alto el fuego, el resto de operaciones del Plan de Arreglo arrastra un retraso de nueve años. Nunca un censo de 200.000 candidatos ha sido diseccionado por la ONU con más empeño y jamás el gasto financiero para la Comunidad Internacional ha sido mayor, la MINURSO ha costado hasta ahora más de 500 millones de dólares. Pero algo más. Ha sido necesario un cuarto de siglo, desde el Censo confeccionado por España como encargo ya entonces de NNUU para el referéndum de autodeterminación en el Sáhara, para que la Comisión de Identificación de MINURSO haya confirmado el mismo con las oportunas correcciones. En efecto, tras varios años de trabajo, ha hecho pública la relación de admitidos como votantes, 86.386 personas. Seguidamente, contra tal lista se ha interpuesto 134.000 recursos: 
- La inmensa mayoría de tales impugnaciones ha sido presentada por el Ministerio de Interior marroquí, colectiva y teledirigidamente, contrariando el Plan de Arreglo, que admite como apelaciones sólo las presentadas individualmente por quienes se entiendan perjudicados.

Las 134.000 apelaciones contra la lista de votantes para el Referéndum en el Sáhara Occidental, se convertirian de facto en una segunda ronda de identificación. En cualquier ordenamiento jurídico nacional, si los ciudadanos recurriesen la mayoria de las resoluciones judiciales, aun estando en su derecho, colapsarian la estructura judicial de ese país. Pero si el empleo de recursos fuese abusivo, teledirigido, y persiguiese precisamente ese colapso judicial, sería legítimo que el ordenamiento jurídico se sacudiera de encima tal fraude.

El contenido del Plan de Arreglo que la Parte marroquí impone es mucho mayor que el continente del propio Plan de Arreglo. No es lícito que el derecho a los recursos se superponga y paralice, una vez más, la estructura y la marcha del Proceso de Paz. El bloqueo no debe dilatar aún más la gravísima situación por la que atraviesa la población en las zonas ocupadas y en las liberadas. Los grandes plazos no deben modificarse por enésima vez. Lo demás es fraude de Ley, la meta no es contribuir activamente a la implementación del Plan de Arreglo, sino precisamente lo contrario, su parálisis.

- En sus últimos Informes, el Secretario General de la ONU da por supuesto que se entrará a conocer de las apelaciones, una a una, que no se incrementará esencialmente el número de equipos de identificación de MINURSO y que, durante ese periodo, no se avanzará en otras fases del Plan de Paz. Por ello prevé un retraso sobre el calendario pactado de dos años al menos otra vez. Finalmente, el Sr. Kofi Annan vuelve a depositar en la intermediación de su Enviado Personal, Sr. James Baker, la superación del marasmo del Plan de Arreglo.

- Este año se ha celebrado en Londres, Ginebra y Berlín sucesivas reuniones entre las Partes, en presencia de Argelia y Mauritania, presididas por el Sr. James Baker, para idear el desbloqueo de los Acuerdos de Houston, contactos que aparentemente no han obtenido resultado.

- Dirigentes políticos marroquíes del más alto nivel han hecho público que, de no incluirse a los apelantes en el Censo definitivo, Marruecos no acudirá a un referéndum. La Parte saharaui ha anunciado la vuelta a las hostilidades si no se produce avances significativos en el Plan de Arreglo.

La última fecha fijada para la celebración del referéndum, la del 31 de Julio del año 2.000 , ha quedado ya claramente superada y sin resultado.

Esta situación, enquistada, es la más grave de los últimos años y puede dar al traste definitivamente con lo avanzado desde los comienzos de las negociaciones en 1.988.

Ante el alarmante retraso que desde 1.992 sufre el Referéndum acordado y la inexistencia aún de fecha para la Consulta, algunos elementos, no todos ellos ni siquiera contem- 
plados en el Plan de Paz, deben ser aplicados inmediatamente, sin dilación alguna, por la ONU, sin someterlos al ritmo general del Proceso. Esos elementos son:

- La inmediata puesta en libertad de los presos de conciencia saharauis en poder del Reino de Marruecos, violación gravísima insostenible por condicionarse a la futura entrada en vigor del Período Transitorio y no a la propia existencia de un Proceso de Paz.

- La defensa de los Derechos Humanos por la ONU de la población saharaui en las zonas ocupadas por Marruecos, garantizando así, como reclama el propio Parlamento Europeo (Resolución de 16 de Marzo de 2.000), "la libertad de expresión, asociación y manifestación para los habitantes del Sáhara" en momentos en que la intifada saharaui está siendo provocada/reprimida "a la timorense", esto es, por milicias de colonos marroquíes arropados por la policía. Advertimos del peligro de timorización del Sáhara Occidental en caso de que la Comunidad Internacional opere exclusivamente a través de la estructura técnica de la MINURSO, manteniendo una campana de cristal e ignorando la realidad que se sigue sufriendo en el Territorio, sin estructuras preventivas ni coercitivas que permitan un control efectivo sobre el mismo.

- La inmediata y efectiva apertura de los espacios terrestre, marítimo y aéreo del Sáhara Occidental y su control por la MINURSO, sin otro límite que la alteración del orden público o la perturbación del ambiente preciso para el ejercicio democrático del voto en el Referéndum. Resulta imposible franquear a la Comunidad Internacional el guetto en que, de hecho, ha convertido el Reino de Marruecos al Sáhara Occidental, sin título alguno que avale tal ejercicio de soberanía.

- La elaboración del censo, la campaña electoral y la formación de electores, la fase de votación y el recuento exigen presencia internacional, siempre ha sido asi en cualquier proceso organizado por la ONU. La excepción, injustificable, está siendo el Sáhara Occidental. Debe acreditarse inmediatamente un cuerpo de observadores para lo que resta de identificación, fase esencial para determinar la propia validez de los resultados. Es absurda la observación internacional en un referéndum si los resultados se han predeterminado en la fase de elaboración de un censo confeccionado a espaldas de la propia Comunidad Internacional.

- La suspensión de la explotación por el Reino de Marruecos de las riquezas naturales del Sáhara Occidental, práctica contraria al Derecho Internacional respecto a los Territorios No Autónomos (según la III Conferencia de Derechos del Mar de Montegobeille, Jamaica, 1.993), y la rescisión de cuantos acuerdos económicos estén vigentes entre terceros países y el Reino de Marruecos sobre tales ámbitos económicos del Territorio, que significan una expoliación legalmente viciada. En su caso, que los cánones de estos terceros países sean devengados a favor de Naciones Unidas para que, como depositaria, los restituya a quien corresponda según el signo del Referéndum de autodeterminación previsto.

Según los Acuerdos de Houston, en el Período de Transición y hasta la Campaña Electoral, hitos trascendentes en sí mismos y engarzados en el espíritu de crear el ambiente 
idóneo para una Consulta libre, transparente y democrática, deben hacerse reales: se abrirá el territorio, se acuertalarán las tropas, se amnistiará por Marruecos a los detenidos políticos saharauis y se intercambiará los presos de guerra entre ambas Partes, se emitirá la lista final de votantes, se cederá la administración marroquí del Sáhara a la MINURSO, se suspenderá por ésta cuantas leyes y medidas marroquíes sobre el territorio pudieran obstruir un referéndum justo, se neutralizará las fuerzas paramilitares marroquíes y se repatriará a más de 150.000 refugiados saharauis.

Queda mucho aún por hacer. Nunca, es verdad, las condiciones geopolíticas fueron tan propicias para devolver la paz a una región ensangrentada, nunca la MINURSO vislumbró tal fuerza ejecutiva ni prestigio para resolver la corrupción y el bloqueo del Plan de Paz.

AUTOSUFICIENCIA.- Sin embargo, con todo, cuando lo pretendido en Houston es que durante el Período Transitorio, se asegure que las bambalinas de la Consulta para el Sáhara sean la seguridad y la democracia, la MINURSO puede caer atrapada en sus propias redes: la autosuficiencia. ¿Le será posible garantizar la neutralización real de la fuerza paramilitar marroquí e imprimir el necesario giro copernicano a una policía que, durante veinticinco años ha campado sobre la violación de los Derechos Humanos fundamentales respecto a lo que han sido considerados súbditos contra su expresa voluntad, para convertirla en una policía de ciudadanos que deben decidir libremente, sin presiones, sobre el futuro de su tierra? ¿Sabrá la MINURSO derogar y sustituir cuanta competencia marroquí afecte a la enorme infraestructura en la que se convierte el Sáhara Occidental como Sede de la inminente Consulta? ¿Podrá garantizar la libertad de movimiento a todos y en todo el territorio?

LO FIRMADO.- ¿Es legítimo no fijarse en cuanto Marruecos ha venido protagonizando hasta ahora, amparándose en que ha firmado en Houston? Si la buena fé se confunde con la ingenuidad, tal vez. Lo firmado..., ¿qué título avaló al Régimen marroquí para invadir militarmente el Sáhara Occidental, cuando el Tribunal Internacional de Justicia decidió que nunca existió vínculos de soberanía entre Marruecos y Sáhara?; ¿qué título de administración -dando por válidos los nulos Acuerdos de Madrid-, justificó el genocidio perpetrado por las tropas marroquíes a finales del 75 - principios del 76 , contra la población saharaui?; ¿qué firma le autorizó a invadir el tercio Sur del Sáhara cuando Mauritania concertó la paz con el Frente POLISARIO y se lo devolvió?; ¿qué título ha esgrimido Marruecos para mantener cerrado a cal y canto, cual cuarto trastero, el territorio durante estos veintitrés años, cometiendo toda serie de tropelías y manteniendo rotas a miles de familias saharauis?; ¿qué razón esgrimió el Régimen marroquí para envenenar los pozos de agua en el desierto con motivo del Plan de Paz de 1.991?; ¿y para forzar migraciones hacia el Sáhara de decenas de miles de marroquíes en el $92 ? \ldots$

NEUTRALIDAD.- La neutralidad de la Comunidad Internacional debe referirse, ni más ni menos, que a la aceptación de cualquier resultado de una Consulta democrática. Pero si, bajo tal principio, asecha el otro muy distinto de la inactividad que, relegando al olvido cuanto ha venido ocurriendo hasta ahora, perpetúe y, aun más, ponga en mayor evidencia, la fragilidad en que arribará, a buen seguro, una de las Partes al Referéndum, el discurso será el de la trampa y, su equivalencia, la abdicación. 
La Comunidad Internacional, antes bien, debe activarse al máximo, precisamente en aras a la neutralidad hacia las Partes, fortaleciendo a la MINURSO, transmitiéndole ayuda y seguridad, como formula para que asuma su total responsabilidad sobre el terreno y respecto a los Acuerdos. En las zonas ocupadas, miles de saharauis bajo una represión erigida en sistema y que deja, tras de sl, torturas, desapariciones forzadas y amenazas. En las zonas liberadas, una repatriación que habrá afectado a miles de refugiados, discurriendo por zonas sembradas entre 5 y 10 millones de minas antipersonales, instalados en nuevos campos sin la infraestructura procurada desde el 75 . A próposito de esto, alguien ha calificado como estadísticamente probable que hasta el $7 \%$ de la población afectada por la repatriación morirá en ella y durante la permanencia en esos campamentos improvisados. El 7\% de 165.000 personas es más de 11.000 . ¿Cómo permanecer impasible para que el débil no llegue al enfrentamiento electoral en las mejores condiciones de igualdad contra el poderoso?

OBSERVACIÓN.- Por ello, deviene necesario que, Plataformas internacionales, misiones (delegaciones), gubernamentales y parlamentarias (Congresos y Senados), Federaciones de Municipios, Colegios Profesionales, Universidades, Sindicatos, sean invitados a la observación a partir de la apertura del territorio en el Periodo Transitorio. Con funciones precisas, bajo la inmediata dirección de MINURSO, pero disponiendo, al tiempo, de su protección:

- Animar a ambas Partes a seguir cooperando en el desarrollo de la letra y el espíritu de los Acuerdos de Houston.

- Reconocer y valorar las condiciones, propicias o no, que se están dando en el interior del Sáhara Occidental. En definitiva, asegurarse de la marcha del proceso, verificar si existe coacción y la calidad de las condiciones para fases claves (culminación de la identificación, apertura del territorio, suspensión de la legislación marroquí, retorno de los refugiados, liberación de presos políticos, garantía de transparencia en el escrutinio y aceptación por ambas Partes del resultado de la Consulta, etc).

- Coadyuvar a incrementar el nivel de confianza en la población concernida por el voto en el interior del Sáhara Occidental.

Del conjunto de lo firmado en Houston y, en particular, del párrafo 3 de la Declaración de las Partes, se desprende que "las facultades y atribuciones de las Naciones Unidas durante el periodo de transición...estén en vigor con miras a garantizar, entre otras cosas, completa libertad de expresión, reunión y prensa, así como la libertad de circulación de personas y bienes dentro del Territorio y para entrar y salir de él, para de esa forma crear un clima de tranquilidad pública...". Ello significa, de un lado, el compromiso de las Partes por crear un clima de tranquilidad y normalidad absolutas como único medio de asegurar la libertad de expresión de la voluntad de los votantes; de otro, ese compromiso incluye el libre acceso al Territorio y la libertad de desplazamiento dentro de él. Esas libertades han de reconocerse con carácter general y no sólo para los votantes, lo contrario convertiría el territorio en un gueto en el que la libertad de elección de los saharauis y su actitud psicológica ante la Consulta se vería gravemente afectada. 
En consecuencia de lo anterior, el acceso de observadores al Territorio no dependería tanto del acuerdo de las Partes, sino de un legítimo derecho de la Comunidad Internacional y por efecto de la simple y llana apertura del Territorio en el Período Transitorio.

Finalmente, vuelve a ser evidente el paralelismo entre lo sucedido en la última época en Timor Este con ocasión de su referéndum de autodeterminación y lo que está acaeciendo en el Sáhara Occidental. Factores como la situación política interna en el país invasor, el miedo insuflado a su población colona para radicalizar la violencia y aún las condiciones geoestratégicas y geopolíticas en la región, han contribuido decisivamente al clima de intimidación y de violencia vividos. Basta fijarse en la escalada de violencia sufrida por la población autóctona saharaui desde el día 22 de Septiembre de 1.999 en las zonas ocupadas del Sáhara, perpetrada por bandas de colonos alentadas por las propias fuerzas de seguridad marroquies. En el recuerdo se ha fijado también el informe emitido a los Ualis marroquies de las zonas ocupadas del Sáhara, con instrucciones sobre cómo "fabricar" votantes. Todo ello es ilícito.

Naciones Unidas no debe desactivar su especial protagonismo en la descolonización del Sáhara Occidental. No sólo por su especial incidencia en todo el Magreb, sino por coherencia ante su responsabilidad presente. En la memoria reciente está el proceso de autodeterminación del pueblo timorense, de la vinculación de la ONU, de la posición nuclear que ha adoptado siempre Portugal como autoridad administradora de iure de Timor Oriental, y la asunción de la Unión Europea de ese proceso como suyo propio, pendiente de autodeterminación y, por tanto, de descolonización.

Pues bien, ese mismo nivel de compromiso de Naciones Unidas y del Parlamento Europeo deben proyectarse hacia el Sáhara Occidental, la responsabilidad de Portugal para con Timor se traslada a España para con el Sáhara Occidental. Sabido es que ambos conflictos, Timor y Sáhara, son gemelos en su etiologia, desarrollo y solución, ambos provenientes de Estados Ibéricos. La ONU sigue manteniendo que la situación actual de España respecto al Sáhara es idéntica a la que existía hasta Noviembre de 1975. Es decir, para Naciones Unidas, España sigue siendo la potencia administradora de iure del Sáhara Occidental (lo que incluye el territorio y la pesca en sus aguas, algo que parecen olvidar nuestros negociadores en los convenios pesqueros con Marruecos). En tanto no se lleve a cabo la Consulta que culmine el proceso de descolonización, no le es dado legalmente a España ignorar ese territorio, no puede desvincularse de tal responsabilidad.

Desde luego, la oportunidad para la ONU es única. La autodeterminación del pueblo saharaui avalaría a Naciones Unidas para asumir, con afianzado prestigio y afinados precedentes jurídicos, procesos de mayor calado y enconamiento. 